\title{
A partilha do sensível na comunidade: interseções entre psicologia e teatro
}

\author{
Tatiana Gomes da Rocha \\ Virginia Kastrup \\ Universidade Federal do Rio de Janeiro
}

\begin{abstract}
Resumo
O objetivo deste artigo é promover uma discussão sobre psicologia e teatro, buscando compreender algumas relações e efeitos possíveis quando ambos se aproximam e se voltam para a produção de subjetividade nas comunidades populares. Um conceito central é o de partilha do sensível, formulado por Jacques Rancière. $\mathrm{O}$ texto discute as formas que a partilha do sensível configura tanto no teatro quanto na psicologia comunitária quando estes se propõem a ser vetores da transformação social, e aponta entraves quando estes se limitam à representação convencional dos conflitos sociais. Outro aspecto considerado é a necessidade de dar mais relevo aos processos de produção de desejo na comunidade.

Palavras-chave: psicologia comunitária; teatro; comunidade; partilha do sensível; produção de subjetividade
\end{abstract}

\begin{abstract}
Sharing the sensible in the community: intersections between psychology and theater. This essay aims to discuss psychology and theater, their relations and possible effects when they are both involved with the production of subjectivity in popular communities. One main concept is the distribution of the sensible, created by Jacques Rancière. The text analyses the distribution of the sensible performed by the theater and by community psychology when they search social transformation. This study's conclusions indicate that the persistence of the conventional representation of the social conflicts constitutes an obstacle shared by psychology and theater, and point to the necessity of giving more relevance to the production of desire in the community.

Keywords: community psychology; theater; community; distribution of the sensible; production of subjectivity.
\end{abstract}

\section{Ensaiar os devires entre psicologia e teatro}

Muitas são as possibilidades de empreender a aproximação entre psicologia e teatro. Por um lado, podemos pensar numa "psicologização" do teatro. Por exemplo, tem-se o teatro psicológico originado das formulações iniciais de Stanislavski (1976). Nesse tipo de teatro e em outros mais contemporâneos que com ele se afinam, preocupa-se com a representação fiel de sentimentos e pensamentos familiares e reconhecidos socialmente, com a expressão dos estados da alma, com o desvelamento do mundo interior de um personagem, seus dramas psicológicos, sua história, e os conflitos decorrentes da relação com os demais personagens. A narrativa submetida ao texto, presa à palavra, induz a caracterizações e explicações psicológicas que acabam por moldar a idéia de um indivíduo centrado numa identidade do eu, que se revela através do trabalho de representação. A esse tipo de teatro são feitas críticas como a de Artaud (1999), que opõe um teatro que põe em cena autos de ocorrência psicológica a um teatro da crueldade ou metafísico.

Por outro lado, podemos falar de uma "teatralização" da psicologia, como é observado na sua apropriação para fins terapêuticos. Nessa esteira encontramos, por exemplo, o psicodrama de Moreno (1987), no qual a ação possui noção central e busca trazer à tona, através de recursos de dramatização, o conteúdo psíquico de indivíduos ou grupos, e confrontá-los consigo mesmos a fim de que as emoções possam ser elaboradas. De forma semelhante, a arteterapia, área em expansão nas práticas psicológicas, também encontra no teatro uma ferramenta na promoção do processo criativo e no fortalecimento da autoestima (Olivier, 2007). Nela, a utilização da produção artística não tem preocupação imediata com fatores propriamente estéticos, voltando-se para o trabalho de descoberta e expressão do eu. 
Em relação a esse tipo crescente de uso da arte em práticas no campo da psicologia, Baptista (2005) lança questões que atentam para os riscos de uma visão essencialista e interiorizada de sujeito que atravessa essas iniciativas. Para algumas propostas observadas entre os profissionais da subjetividade, a arte seduz pela crença na sua capacidade de desvendar os mistérios da alma e de implodir os obstáculos que impedem as expressões genuínas, como se o espaço interior e exterior ao indivíduo estivessem já claramente definidos. Evidentemente, nem todos os trabalhos de produção de subjetividade através da arte enveredam por esse tipo de concepção ou buscam tais efeitos depuradores. No entanto, percebemos que essas iniciativas se baseiam num modelo em sintonia com a concepção de sujeito predominante na história da psicologia, que ganha matizes diferentes ao redor de uma mesma idéia: a noção de um eu constituído, localizável, a ser descoberto, a ser nomeado e a ser explicado. Seja afirmando o sujeito do conhecimento, seja pressupondo-o senhor de seus domínios e auto-consciente, seja considerando-o cindido e não totalizável pela consciência, ou mesmo falando de um sujeito sócio-histórico, na tradição da psicologia se mantém a idéia de um núcleo essencial e estável, que ora assume o lugar de estrutura, ora de uma imagem de si, ora de um centro autônomo da psique, que em todo caso indica uma identidade do sujeito naquilo que ele reconhece como sendo ele próprio.

O conceito de produção de subjetividade, desenvolvido por Deleuze e Guattari (1995), tem o intuito de dar outro relevo ao entendimento da subjetividade, termo tradicionalmente reduzido a uma dimensão solipsista e interior do indivíduo. Para os autores, a subjetividade passa a ser entendida como efeito de máquinas (de ver, de perceber, de sentir, de pensar, de falar, etc.) em ação conjunta, que são tanto sociais quanto políticas, econômicas, culturais, clínicas, midiáticas, etc. Procuraremos discutir os processos de subjetivação que se produzem entre a psicologia e o teatro quando o plano de interseção ${ }^{1}$ entre eles é a vida na comunidade. $\mathrm{O}$ conceito de comunidade dá margem a diversas compreensões, que também buscaremos discutir brevemente.

No que diz respeito às formas que a relação psicologia e teatro podem assumir, não é nem no sentido de uma "psicologização" do teatro nem no de uma "teatralização" da psicologia, como discutido acima, que procuramos nos mover. Compreendemos que estes são dois campos distintos, e que neles existem diversos e diferentes modos de fazer teatro e psicologia. Procuramos investigar formas de encontro entre ambos que os potencialize, ao mesmo tempo, prolongando seus limites e reinventando-os mutuamente. Assim, pensamos nas possibilidades de um devir-artístico da psicologia e um devirpsicológico da arte, sem que isso implique a sujeição de um domínio ao outro, a submissão a um modelo, uma mera troca ou imitação, mas um compartilhamento de forças e de afetos, a abertura de uma fronteira na qual podem acontecer passagens de um território ao outro. Devires, para Deleuze (1998), são processos de dupla-captura, em que cada termo toma do outro algo que o faz arrastar para fora de seus contornos originais e permite a criação de novas formas. As relações em devir ou dupla captura apontam para uma exterioridade, para um movimento tecido no entre, uma multiplicidade que não diz respeito à quantidade, mas às variâncias, às mutações.

No entanto, isso é algo a ser exercitado, arriscado, ensaiado. Falamos de uma psicologia que se faz junto às associações e grupos comunitários, que explora as formas que a vida organiza no espaço e tempo, que acompanha as pluralidades e as diferenças que podem ser encontradas num território, num certo comum. Apostamos numa psicologia comunitária que, mais que se propor a fazer diagnósticos, apontar carências e prescrever soluções, se propõe a cartografar suas virtualidades, suas linhas de fuga, a cavar espaços onde se permita experimentar o dissenso, os vazios de sentido, a criação de novas formas de sociabilidade, ou seja, novas maneiras de partilhar o comum, que inevitavelmente esbarram na dimensão política do viver junto.

Por outro lado, falamos de um teatro que se aproxima daquele experimentado por Pelbart em seu trabalho junto à Companhia Teatral Ueinzz, formada por atores usuários de serviço de saúde mental. Em vez de itensificar psicologicamente os traços de cada um, nos seus dramas íntimos, iluminando a suposta verdade psíquica interior do sujeito, o teatro faz esses traços "reverberarem com a cultura como um todo e experimentar variações inusitadas" (Pelbart, 2000, p. 106). Perseguimos um teatro que pretenda se abrir ao que esteve de fora ao longo de sua história (Guénoun, 2004). Um teatro do homem comum, onde a vida seja posta em cena, não no sentido de ser explicada, mas de ser reinventada, de compor novas partilhas do sensível, de misturar os tempos e as ocupações, de libertar os corpos de uma condição histórica de passividade intelectual e sensível:

A arte do teatro deve se abrir aos fluxos da vida que continua estranha a ele. [...] É a cena o que é preciso abrir; a cena como espaço prático, material. [...] É preciso trazer os homens para a cena. Não sua imagem, mas suas singularidades e seus grupos, efetivamente, vivos. É preciso abrir as cenas à vinda daqueles que foram delas banidos: os ditos não-atores, os não-artistas.

(Guénoun, 2004, pp. 156-157)

Falamos da tentativa de abertura do teatro realizada por alguns artistas e grupos que não se satisfazem com o confinamento da arte ao modelo da identificação e da representação. Em seu desafio atual, o teatro se propõe a compor novas formas de experimentar a vida, de agenciar o desejo que emana dos grupos, dos povos, dos corpos coletivos, enfim, ele se afirma em seu devir-político como vetor de transformação social.

\section{A partilha do sensivel}

Quando psicologia e teatro se propõem a intervir na direção da transformação social, podemos mais claramente inferir uma dimensão política e estética em comum entre ambos, tomando de empréstimo o conceito de partilha do sensível. Com ele, Rancière (2005a) busca afirmar uma dimensão estética da política, se referindo, ao mesmo tempo, a duas noções: a de que existe participação num plano comum, que dá forma à comunidade, e ao recorte desse comum sensível em partes espaço-temporais definidas:

A partilha do sensível faz ver quem pode tomar parte no comum em função daquilo que faz, do tempo e do espaço em que essa atividade se exerce. Assim, ter essa ou aquela "ocupação" define 
competências ou incompetências para o comum, dotado de uma palavra comum etc. (Rancière, 2005a, p. 16)

A partilha do sensível faz ver, concomitantemente, a existência de um plano comum sensível e espaço-temporal dos corpos, das práticas, dos discursos e dos processos de subjetivação, e a segmentação desse comum em partes definidas, seu recorte em tempos e ocupações específicas, suas relações de inclusão e exclusão, de interioridade e exterioridade, os regimes que organizam modos de ver e de dizer e que deixam folgas nas quais a negociação de sentidos é possível. Essa partilha, como diz Rancière, é algo em que incidem tanto a política como a estética, pois para ele "a política ocupa-se do que se vê e do que se pode dizer sobre o que é visto, de quem tem competência para ver e qualidade para dizer, das propriedades do espaço e dos possíveis do tempo" (Rancière, 2005a, p. 17). A partilha é estética ao ser efetuada num comum sensível,

como um sistema das formas a priori determinando o que se dá a sentir. É um recorte dos tempos e dos espaços, do visível e do invisível, da palavra e do ruído que define ao mesmo tempo o lugar e o que está em jogo na política como forma de experiência. (Rancière, 2005a, p. 16)

No que diz respeito ao plano comum, é necessário compreendê-lo em sua singularidade. O comum não se coloca como um plano geral de igualdade e identidade entre membros, uma vez que ele não é a priori ou natural, mas algo a ser sempre constituído. É dessa forma que Rancière fala de uma estética na base mesma da política, uma compreensão que não é uma estetização da política como partido, sua captura pelo Estado ou pelo capital ou uso pela vanguarda. Ela se aproxima antes de um determinado regime dos recortes e das formas resultantes que possibilita e regula a relação com o sensível, que define como e o quê pode ser visto e ouvido, incluído ou excluído, compondo o próprio sentido do político.

A partir dessa aproximação do estético ao político podese pensar a questão da arte, ou antes, de suas práticas, em relação com as formas de segmentação e visibilidade que ela introduz no comum, sendo elas formas de agir que entram em composição com outras formas de agir, com modos de ser e modos de visibilidade, interferindo na distribuição geral desse comum. Assim, Rancière esclarece o caráter político da arte, entendida como prática estética: a arte não é política no sentido da transmissão de mensagens, como meio de divulgação de palavras de ordem, panfletarismo, pregação ou messianismo. A estética da política não se faz por uma estetização da política - sua captura pela unicidade do sentido, pela totalização da experiência, como usada nas campanhas do fascismo. A arte é política mesmo antes de qualquer tentativa nesse sentido, mesmo quando pretende se afastar radicalmente de qualquer intervenção social, de qualquer compromisso, qualquer aliança.

Segundo Rancière (2005a), o regime estético das artes, surgido na virada dos séculos XVIII e XIX, modifica o estatuto da arte (baseada, até então, numa distinção dentre as maneiras de fazer, nas quais às artes cabia a qualidade da imitação), passando a distingui-la em função das relações que ela estabelece com um modo de ser sensível próprio a seus produtos, a um regime específico do sensível. Esse regime define uma experiência sensível que não se reduz à percepção natural, posto que é vivida fora das condições normais da experiência sensível e das hierarquias às quais a arte estava submetida. $\mathrm{O}$ sensível assim compreendido é marcado pela presença de uma "potência heterogênea, a potência de um pensamento que se tornou ele próprio estranho a si mesmo" (Rancière, 2005a, p. 32), o que remete ao reconhecimento de uma qualidade irrepresentável do sensível, de sua potência de diferenciação. Ele se torna o único núcleo identificador das vontades e modos de fazer artísticos, por assim dizer, sua única referência.

O regime estético das artes é aquele que propriamente identifica
a arte no singular e desobriga essa arte de toda a qualquer regra
específica, de toda hierarquia de temas, gêneros e artes. [...]
Ele afirma a absoluta singularidade da arte e destrói ao mesmo
tempo todo critério pragmático dessa singularidade. Funda, a
uma só vez, a autonomia da arte e a identidade de suas formas
com as formas pelas quais a vida se forma a si mesma. (Ran-
cière, 2005a, pp. 33-34)

Sob esta perspectiva, o regime estético da arte, ao mesmo tempo em que se liberta de padrões e regras hierárquicas para a criação, identifica a arte com as próprias formas assumidas pela vida, com as manifestações da vida de um povo. Desta maneira, o que assinala o advento da revolução da experiência sensível é a emancipação estética através da qual um trabalhador se torna capaz de se forjar um novo corpo, com o que ele pode ir além dos esforços musculares capturados pelo capital e descobrir novas formas de relação com a vida e com a sensibilidade, rompendo com seu lugar pré-determinado na configuração espaço-temporal da comunidade, "separando seu olhar contemplador dos braços que trabalham para o patrão" (Rancière, 2005b, p. 05). Em oposição ao estado de dominação, no qual o pensamento e o corpo sensível se encontram subtraídos de potencial criador (a atividade da matéria é mecanizada e o pensamento é marcado por sua passividade improdutiva), deve ser desenvolvida uma educação estética que restitua o caráter ativo do pensamento e a ativação da receptividade sensível do corpo.

Nesse sentido, o regime estético se constitui através de uma aparente contradição, pois ele compreende a arte como forma autônoma da vida. Isso vale afirmar, ao mesmo tempo, dois aspectos divergentes: a autonomia da arte e sua identificação com o processo de criação da própria vida. Dessa forma, o estético é dotado de um duplo potencial de emancipação. Por um lado, esse potencial reside na ociosidade, na recusa a qualquer forma de subordinação ou de funcionalidade, na resistência ao controle social - se aproximando assim da postura do trabalhador que reivindica a si o direito ao ócio e à contemplação, à liberdade de indiferença. Por outro lado, o regime estético advoga a autosupressão da arte em favor de sua integração plena na construção da vida comum renovada e que torna indistintos arte e política, trabalho e lazer, enfim, promove a união dos contrários.

É precisamente essa habilidade de pensar as contradições que define a estética. E é esse paradigma que atesta a idéia de uma política da arte que independe mesmo da vontade do artista de refutá-la ou de fazê-la servir a uma causa política. No entanto, essa contradição que a funda deu origem a duas formas 
políticas da estética, que marcam a divisão, por sua vez, entre os partidários da "arte pela arte" e os partidários da sua missão social. Essa dicotomia acirrada é fruto de uma incompreensão do fundamento do regime estético, que toma por mutuamente exclusivas duas premissas que se interpenetram, apesar de se afirmarem em seus sentidos opostos.

Rancière alega que não pretende definir o que ou como deve ser uma política da arte, mas aponta alguns perigos nos rumos tomados na arte contemporânea. Nesse sentido, ele aponta o risco de anular na arte a potência do encontro dos heterogêneos, ao se furtar à ocupação dessas "formas de recorte do espaço sensível comum e de redistribuição das relações entre o ativo e o passivo, o singular e o comum, a aparência e a realidade" (Rancière, 2005b, p. 10). Um certo tipo de arte crítica que busca produzir conhecimentos ou representações teima em persistir, se limitando ao trabalho de separação das aparências da realidade e não atentando para as possibilidades de embaralhar as próprias relações e regulações entre ambas. A suspensão das explicações sobre as forças objetivas de produção da realidade podem dar lugar àquilo que Rancière defende como realmente político: "não o conhecimento das razões que produzem tal ou tal vida, mas o confronto direto entre uma vida e o que ela pode" (Rancière, 2005b, p. 16).

No conceito de partilha do sensível, encontramos uma fronteira entre estética e política na qual podemos pensar psicologia e teatro. A psicologia se faz política ao promover deslocamentos, inventar novos problemas, construir entre os sujeitos implicações que apontem para outros mundos possíveis, dada a produção de desejo imanente ao coletivo: desejo de transformação não apenas das condições físicas do ambiente, geralmente perversas e indignas em vários aspectos, mas também desejo de criar novas formas de (con)viver, formas mais abertas, artísticas. O sensível é a matéria na qual opera a subjetividade, e a psicologia também busca ativar a receptividade do corpo, sua relação estética com o mundo.

Por sua vez, o teatro participa da partilha do sensível ao produzir em suas ficções o embaralhamento das legitimidades, das identidades, das atividades e dos espaços, dando a pensar uma reconfiguração do comum, uma repartilha do social. O próprio momento do encontro entre palco e platéia promove essa partilha, essa reconfiguração da experiência política e sensível. Para Guénoun (2004), ao teatro cabe a tarefa de se abrir para o que está à sua margem, o que lhe está fora. Compreendemos que essa abertura contemporânea do teatro esteja se concretizando quando as minorias que habitam as comunidades populares são convidadas a também tomarem parte na cena.

\section{O teatro e a comunidade, a psicologia e a comuni- dade}

Assim como Rancière, Guénoun (2003) também se volta para a identificação de uma política constitutiva da experiência teatral em termos da sua própria disposição física, independentemente do que se propõe a ser representado. Alguns elementos analisados por Guénoun buscam enfocar esse pressuposto político.

Antes de qualquer coisa, o teatro requer um público reunido presentemente, e essa convocação pública é, de saída, política. O próprio termo atual, teatro, se mantém como resquício dessa ênfase na assembléia que vem ao encontro da experiência teatral: o théatron é, originariamente, o espaço físico de onde se assistia a representação - de onde se vê, eis sua tradução mais próxima. $\mathrm{O}$ ato político dessa reunião é originário, e segundo Guénoun, a assembléia disposta já contém em si os gérmens do político. A publicidade do chamado entra em relação com questões políticas da cidade, de circulação, fiscalização, propaganda ou manutenção da ordem. Para o autor, esse esquecimento das origens do teatro e da relevância da presença do público acompanha os movimentos da sua história, cuja ênfase vai, gradualmente, se deslocando da platéia e da globalidade do espaço para o palco, lugar destinado ao representado.

A escolha do local da representação também é política: longe ou afastado do centro da cidade, estabelece uma relação espacial com os grupos que a habitam. Assim como a escolha da hora e da duração: durante o dia, horário destinado ao trabalho, ou à noite, reservado ao descanso. $\mathrm{O}$ teatro se insere no espaço de organização da cidade, e o governo não lhe é indiferente, seja para apoiá-lo, seja para pôr-se em alerta.

Guénoun dá realce à ordenação do teatro pela arquitetura. O círculo que lhe caracteriza o espaço é seu formato originário. Por ser esta a formação que provê a melhor disposição para ver e ouvir uns aos outros, o autor aponta a circularidade como uma pré-disposição política. O formato circular sofre, no entanto, distorções no tempo. Seu extremo oposto é a sala retangular, que denota uma certa frieza do espaço, em função da separação e distância marcantes entre palco e platéia, embora favoreça a visão do todo da cena.

Guénoun discute então a importância originária da circularidade: o círculo permite que o público não veja apenas a cena, mas que se veja, se diferencie da massa. Há o desejo de sentir e reconhecer sua existência coletiva, de perceber o contágio de suas reações frente ao representado. O público quer experimentar seu pertencimento coletivo, compartilhá-lo, e em um certo plano, ele compõe uma forma de comunidade. A reunião do público é indício da manifestação de um desejo de comunidade. As alterações no formato circular do espaço físico do teatro podem ocorrer tanto através do fracionamento do círculo (quando o palco se opõe ao resto, se eleva, e os efeitos de luminosidade põem a platéia gradualmente nas sombras, em relação à iluminação direta do palco) como por seu achatamento (o palco se estende em largura e em profundidade, tornando-se pouco a pouco frontal. No entanto, esse caminho não é linear: há, na história do teatro, momentos de irrupção bruta, quando da afirmação do espaço político e do desejo comunitário. São momentos nos quais o formato circular se renova e se recompõe.

Apesar de identificar os sinais do político na experiência teatral, pela reunião do público que é potencialmente dotado de ação política, Guénoun não compreende que fazer teatro seja fazer política da mesma maneira que a política propriamente dita. No entanto, o autor pensa na relação entre a baixa afluência contemporânea aos teatros e o desapreço pelo exercício do político no cotidiano da sociedade: essa abstenção afetaria a ambos, pois o público só vai ao teatro quando quer ser politicamente ativo.

Assim como a psicologia, o teatro também buscou pensar 
suas implicações políticas e suas relações com o social, ainda que em meio às dificuldades de compreensão e conceituação. É dentro do campo do teatro popular que as relações entre teatro e comunidade foram pensadas. Por um lado, existem companhias de teatro itinerantes, formadas por artistas vindos de lugares diferentes, que se reúnem e apresentam suas produções nas comunidades populares, no intuito de incentivar a discussão e a participação comunitárias. Por outro lado, existem aqueles grupos de teatro que nascem das próprias comunidades, e cuja produção está intimamente relacionada ao seu cotidiano. Esse tipo de teatro tem sido denominado teatro comunitário. No Brasil, este se desenvolveu caminhando ao lado das ações na área da educação, muitas vezes na ação pedagógica conscientizadora baseada na educação popular de Paulo Freire. Segundo Arias e Nolasco (1997), o teatro comunitário surge como instrumento e técnica para uma educação comunitária. Nele, há um comprometimento do grupo de artistas com as causas da comunidade, seus interesses, e a vontade de refletir sobre a realidade da mesma. Acredita-se que a mudança é possível pela identificação dos mecanismos opressivos e da possibilidade de suplantá-los.

O objetivo no teatro comunitário é promover uma mobilização dupla, tanto de quem faz quanto de quem assiste, proporcionando um aprendizado mútuo, uma partilha de pensamentos e desejos através da ultrapassagem dos limites estéticos da arte. Na pedagogia teatral existe tanto a preocupação com o processo quanto com o produto do trabalho artístico, buscando uma tentativa de conciliação entre ambos. É comum às metodologias utilizadas nessas práticas proporcionar um momento de diálogo entre grupo teatral e o público sobre a experiência, após a apresentação da peça.

Ao que parece, mesmo envolto em propostas de transformação da realidade, o teatro (propondo-se, ou não, comunitário), não procurou compreender a comunidade como algo específico, o que nos faz crer que em sua concepção a comunidade se reduz a qualquer popular que conviva com a pobreza, com carências, com a existência de problemas em comum a serem resolvidos, com a opressão, uma vez que esses são os poucos aspectos recorrentes nos estudos em teatro que tratam da questão. A compreensão da noção de comunidade, como área urbana desfavorecida economicamente, sua dimensão formal, não é a única possível para a exploração de suas virtualidades.

Ao nos voltarmos para as relações entre a psicologia e a comunidade, distinguimos no campo da psicologia social um ramo denominado psicologia comunitária, cujas origens brasileiras remontam aos anos 1960. Ao contrário do que percebemos nas teorias e práticas de agenciamento entre o teatro e a comunidade, na psicologia comunitária o conceito de comunidade é alvo de investigação, ainda que tardio. Segundo Sawaia (1996), o conceito é ausente na história da psicologia até a década de 1970, quando as primeiras iniciativas da área comunitária se fizeram. Até então, a comunidade era entendida apenas como uma das formas intermediárias entre o indivíduo e a sociedade. $\mathrm{O}$ termo comunidade voltou à tona na contemporaneidade, longe de ser um consenso entre aqueles que nela atuam, o que denota as divergências quanto às formas de aproximação com o espaço comunitário. Vejamos algumas transformações que acompanharam a definição do termo.

Com as transformações em direção à emergência da psicologia social crítica na década de 1980, o morador da comunidade passou a ser considerado em sua dimensão política e de agente ativo e modificador das estruturas sociais. No entanto, para Sawaia, em meio a essa mudança conceptual, a psicologia ainda se encontra em busca de superar uma visão de comunidade como una e homogênea, em proveito de uma concepção que concilie as aspirações individuais e coletivas. Para Góis (2005), o espaço físico-social é um dos pressupostos fundamentais, englobando aí tanto a questão da proximidade física quanto a inclusão numa mesma realidade social.

Observamos que as tentativas de definição do conceito de comunidade para a psicologia, mesmo que variadas e imprecisas, são construídas a partir de uma compreensão sociológica original, que relacionou comunidade e sociedade como categorias esquadrinhadas por uma regulação social e disciplinar, compartimentada. Neste modelo de entendimento da organização social, as relações entre os indivíduos são mediadas por um dispositivo transcendente que é espacializado no entorno da vizinhança - o que elimina as possibilidades de constituição do comum, como entendido por Negri (2005). Os dispositivos que fundaram a comunidade nasceram do programa disciplinar do biopoder e que na contemporaneidade tem adquirido outras variações em relação ao controle. Mesmo quando se enxerga a comunidade como espaço de comunhão e sentimentos puros, tal como propôs Tönnies (1887/1989), de acordo com os poderes administrativos o espaço produtivo da comunidade não deixou de ser cooptado como instância intermediária da sociedade. São níveis de mapeamento em linhas concêntricas, em que num extremo tem-se o indivíduo, cuja individualidade está protegida na comunidade, e no outro encontra-se a máquina estatal da administração pública. O próprio espaço aberto e territorial da comunidade foi assumido funcionalmente como uma instituição social, ainda que não tenha funcionado sob a lógica do enclausuramento que caracterizou a sociedade disciplinar. Esta análise impede qualquer tipo de entendimento naturalizante da comunidade, como algo que se configura espontaneamente em decorrência da convivência íntima sob um mesmo espaço.

No entanto, mesmo que o conceito de comunidade que aqui descrevemos como sociológico-disciplinar esteja ficando para trás, o território urbano concreto que ele buscou cobrir permanece em definitivo. A questão urbana hoje passa necessariamente pela urgência de pensar a realidade das favelas, morros, periferias, comunidades populares, enfim, são várias as formas de se referir hoje a esse território forjado na margem do regime de produção capitalista. Esses lugares crescem e ganham cada vez mais visibilidade, suscitando ora o medo nas classes sociais média e alta, com as quais divide o uso dos espaços urbanos, ora a curiosidade nessas mesmas classes, em relação à criação de novos estilos de vida gerados nas comunidades, e que hoje se vinculam sobretudo à arte e à cultura. Assim, acreditamos que, longe de estar esgotada pelo caráter institucional com o qual a comunidade foi investida pelo poder disciplinar (posto que a crise das instituições como a escola, o hospital psiquiátrico, etc., são marcas da sociedade de controle), a comunidade popular é hoje um território, no sentido empregado por Deleuze e Guattari 
(1995), em constante ebulição de forças micropolíticas.

O princípio da identidade, considerado por diversos autores como articulador da comunidade, tem cedido lugar à noção de constituição do comum. Leva-se em consideração não os elementos de representação de um coletivo, mas uma zona de ressonância:

Aquilo que supostamente se perdeu da "comunidade", aquela comunhão, unidade, co-pertinência, é essa perda que é precisamente constitutiva da comunidade. Em outros termos, e da maneira mais paradoxal, a comunidade só é pensável enquanto negação da fusão, da homogeneidade, da identidade consigo mesma. A comunidade tem por condição precisamente a heterogeneidade, a pluralidade, a distância. [...] a comunidade, na contramão do sonho fusional, é feita da interrupção, fragmentação, suspense, é feita dos seres singulares e seus encontros. Daí porque a própria idéia de laço social que se insinua na reflexão sobre a comunidade é artificiosa, pois elide precisamente esse entre. Comunidade como o compartilhamento de uma separação dada pela singularidade. (Pelbart, 2003, p. 33)

A constituição do comum é uma idéia que tem sido utilizada para pensar o desejo e o processo de formação de comunidades, de redes associativas de produção comum: “A propriedade comum não passa simplesmente pelo Estado, passa pelo exercício que as singularidades fazem desse espaço comum, pela maneira de exercer esse espaço comum" (Negri, 2005, p. 5). A singularidade expressa na idéia de comum de Negri ocorre na formação de um espaço cooperativo onde as singularidades possam se encontrar e assumir juntas a confecção de um território, mas esse processo não se dá pela conjunção de individualidades ou pelo reconhecimento do outro como idêntico a si. O reconhecimento do outro que Negri descreve se inscreve no plano de pluralidade pré-formal, no plano das forças moventes que atravessam ambos ao mesmo tempo, apesar de originarem individuações diferentes.

Para além da organização da sociedade civil em instituições já demarcadas, Negri traz a noção de multidão como novo coletivo social, dotada de um poder constituinte que não está submisso ao domínio do instituído. Multidão é um termo tradicionalmente utilizado de forma pejorativa e negativa, historicamente compreendido pelas ciências políticas como massa irracional e pré-social a ser dominada e adestrada, a fim de se tornar sociedade. Hoje, com a reconfiguração das classes sociais, cujos contornos específicos encontram-se indefinidos em função das novas dinâmicas do trabalho, e com a emergência de um proletariado imaterial, a questão da multidão reaparece. A potência da multidão reside em seu poder constituinte, que por sua vez é um exercício de resistência na invenção de formas democráticas de participação política. A multidão opõe-se à massa pelo fato de que não vem a constituir uma unidade nem é homogênea. $\mathrm{O}$ poder constituinte da multidão pode firmar acordos e regras, mas estes são contingenciados temporalmente a partir de questionamentos e reavaliações, e redefine a concepção de poder político, não mais reduzido ao seu caráter representativo. A expansão de seu poder se expressa através de atividades empreendedoras que atravessam o território social, político, econômico, por atividades que reorganizam as situações de produção da vida e do social, sem, no entanto tomarem por princípio único as demandas econômicas.

A potência da multidão reside justamente na riqueza de sua heterogeneidade, suas singularidades, que circunstancialmente se agenciam através de esquemas de cooperação, redes autônomas que se cruzam. É dessas formas associativas e solidárias que advém o poder constituinte da multidão, sua capacidade de resistir. A resistência é colocada tanto no sentido de se opor a uma racionalidade perversa como no sentido de inventar uma outra, um empreendimento biopolítico não no sentido de um poder sobre a vida, mas de um poder da vida. Pelbart afirma: "Biopoder como um regime geral de dominação da vida, biopolítica como uma forma de dominação da vida que pode também significar, no seu avesso, uma resistência ativa, e biopotência como a potência de vida da multidão" (Pelbart, 2003, p. 86).

\section{Para concluir}

A modalidade da relação entre psicologia e teatro de que falamos aqui afirma a potencialidade do encontro entre práticas que são tanto estéticas quanto políticas, agenciando processos de subjetivação nas comunidades em que eles se produzem. Tanto a psicologia quanto o teatro trazem consigo concepções e expectativas sobre a comunidade, e têm formas específicas de ativá-la, de convocá-la, de compô-la. Ambas devem trabalhar com o desejo de comunidade, desejo de constituí-la, de dar alguma consistência ao coletivo, de partilhá-lo de acordo com certos meios e horizontes próprios. Quem faz teatro deseja um público e deseja comparsas que criem em conjunto. Quem trabalha com psicologia comunitária deseja articular grupos. Há desejo de constituir comunidade, e há desejo que emana da comunidade quando ela se forma, desejo que se torna matériaprima para ambos.

Enfim, esperamos apontar saídas, lugares diferentes. O teatro e a psicologia vêm participando das formas gerais de partilha do sensível, tanto no que diz respeito às formações e modulações históricas do social quanto às partilhas que se operam no plano comum do presente, interferindo na organização e configuração das atuais divisões espaço-temporais. Muitas são as possibilidades de ambas fecundarem os coletivos e as comunidades, reunidas fisicamente ou não, no sentido da construção de novas políticas sobre o sensível e a alteridade, bem como da construção de outras compreensões sobre o próprio campo do político.

Talvez se faça ainda necessário à psicologia e ao teatro se contaminarem pela dimensão política, tal como vemos na proposta de Rancière de partilha do sensível. O político diz respeito à participação na confecção do sensível comum, o que não se confunde com os partidarismos e palavras de ordem. Essa participação pode ser empreendida tanto no sentido de desregulação das divisões molares, como dizem Deleuze e Guattari (1995), promovendo o embaralhamento das identidades e das ocupações, ou no sentido de reforçar a segmentaridade, quando as identidades e a lógica das relações que as definem são confirmadas. A constituição do comum se propõe a embaralhar quando rompe com as divisões, repartilhando os limites e os possíveis de existência e os modos de convívio e cooperação 
social, formando redes solidárias de ampliação dos territórios e aumento da qualidade da produção inventiva.

As tentativas do teatro de se abrir para o popular e o político correm muitas vezes o risco de confirmar os modos de representação da realidade em termos antagônicos e com uma visão centralizadora e transcendente do poder, o que limita o espaço de invenção de outros modos de apreensão e participação nas relações produtoras do comum e do social. O engajamento do teatro popular e comunitário com as questões sociais corre o risco de, mesmo assumindo o partido do povo, não causar grande impacto no que diz respeito à produção da diferença. É o que Nunes (2004) discute no que denominou de crítica amorosa ao teatro do oprimido (TO), criado por Boal (1980):

O TO é um teatro e uma tecnologia "psi" que permite à militância se manter no nível das representações molares. Por isso, também tem acolhida entre trabalhadores sociais: o TO diverte, debate, bota alguns não-ditos (mas já pensados) em pauta, mas protege da vertigem da variação das linhas, protege daquilo que ainda não se pensou (virtualidades/marcas que pedem atualização). Assim, tudo tem que estar entendido no teatro do oprimido: tudo conscientemente apreensível, porque se acredita e se aposta em mudanças na ordem de referência molar. (Nunes, 2004, p. 142)

Nas formulações de Boal (e de outros que se afinam com suas propostas), a política por onde circula o desejo do povo é sempre macropolítica, reduzida e reforçadora do binarismo opressoroprimido. Ao mesmo tempo em que persegue a libertação, se apega aos modelos identitários, e a solução é a tomada de poder do opressor, sua destruição para assumir os poderes que ele detém, o que mantém a lógica binária. Rolnik (2003) faz uma análise oportuna dos mecanismos de manutenção da dicotomia opressor-oprimido e argumenta que há uma má compreensão acerca da crueldade como dimensão da vida. Para a autora, a crueldade é entendida como processo no qual as configurações da matéria-forma vigente são postas à prova no embate com a alteridade e desconstruídas para dar passagem ao surgimento de novas figuras da subjetividade. No entanto, essa crueldade é significada como luta entre identidades opostas que disputam sua preservação e controle pelo poder, o que oblitera a dimensão micropolítica das forças de mutação que habitam os interstícios do corpo social, interrompendo a resistência e a criação:

Nesta política da resistência reativa, a multiplicidade de forças em jogo é silenciada e subordinada a seu enquadramento em apenas duas figuras subjetivas: a vítima e/ou o algoz, avessos especulares de uma mesma lógica. [...] Ressentimento e vingança: políticas de resistência da vítima que respondem em espelho àquilo mesmo que pretendem combater - a lógica da violência e seus principais protagonistas, o par vítima/algoz, que tais políticas alimentam voluptuosamente. (Rolnik, 2003, Políticas da resistência: "o acontecimento Lula", para. 5)

Eis uma questão fundamental: como sair das fórmulas enrijecidas pelo teatro popular ou comunitário, e ainda se manter dentro do plano político? Como manter as intensidades políticas e sociais da arte de outra maneira? Pensando no teatro e na arte, mas também incluindo as propostas da psicologia social e comunitária: como recolocar os conflitos, e sair da lógica binária? Enfim, "como fazer valer o trabalho subterrâneo de uma variação livre e presente, que se introduz entre as tramas da escravidão e transborda o conjunto?"2 (Deleuze, 1979, p. 123).

Em meio aos embates da psicologia e do teatro entre as formas instituídas e as forças instituintes que os atravessam, algo escapa, pois pensar as transformações no social pelo político não é apenas uma questão de segregação econômica e cultural, mas de caminhos que o desejo busca percorrer. O que a multidão deseja, estará presente na arte? Será encontrado nos agenciamentos com a psicologia? Quem é hoje esse homem comum que faz parte do povo? Muito se pergunta se o indivíduo pouco instruído intelectualmente e com poucas oportunidades culturais na vida estaria em condições de assimilar uma arte mais refinada e sutil. Mas a pergunta mais interessante não é se ele está pronto para a experiência com a arte, que tampouco é questão de assimilação, mas se nela ele encontra elementos que venham a lhe despertar as sensações de potência adormecidas no seu corpo, e isso não tem necessariamente a ver com escolaridade ou inteligência, mas com a produção e desejo. O desejo, para Deleuze (1998), é sempre revolucionário e coletivo, posto que sua eclosão é ao mesmo tempo a construção de um plano imanente comum que diverge das estruturas estabelecidas, e por meio dele uma nova visão do mundo é possível.

Com Nunes, pensamos as rachaduras e as linhas de fuga aos princípios de totalização da experiência teatral na unidade do sentido. Ainda discutindo os entraves e as saídas do teatro do oprimido, ela comenta:

Daí se falar em "analogia", em "identificação", e "reconheci-
mento", quando se poderia falar de transversalidades: o que está
atravessando esse campo? Como facilitar - ou não atrapalhar
- agenciamentos? Como fazer uma leitura do que se passa
numa dimensão molecular, por exemplo, em uma sessão de
teatro-fórum? (Nunes, 2004, p. 134)

Para Nunes, contra a sobrecodificação e a reterritorialização da invenção, o melhor remédio é a peste artaudiana, é a contaminação, pois se não há, tanto no teatro como na psicologia, formas de prevenção e proteção ao que boicota, a saída possível é devir-minoritário; furar os bloqueios, não pela oposição frontal com a molaridade do teatro ou da psicologia, mas deixando a diferença fluir por dentro, cavando espaços de vazio a-significantes no meio do campo para que daí possa se insinuar o novo (Nunes, 2004).

Como Rolnik, pensamos os processos de transformação social, que seriam efeitos da acumulação e precipitação das linhas de molecularidade desenhando novas formas de sociedade. É nesse sentido que pensamos os agenciamentos entre psicologia e arte, quando esta se coloca como possibilidade de rastreamento das mutações de sensações em curso no presente e ao mesmo tempo constituindo um plano comum sensível, onde a psicologia pode empreender suas próprias formas de resistência e criação na comunidade.

Compreendemos que o desejo de comunidade não é desejo de afirmação das suas maneiras de ser, de fortalecimento de sua identidade, mas desejo de abrir espaço para a passagem dos devires que ela comporta. Não há transformação social 
possível cujas estratégias principais estejam assentadas sobre a preservação do que já existe. É preciso que a psicologia procure efetuar suas potências pelo encontro dos heterogêneos que estão no avesso nas representações. Assim como para as artes, a repartilha emancipatória do sensível não é um esforço por separar as aparências das realidade, é antes embaralhar as relações e regulações que se confundem entre ambas e explorar o plano de consistência que as fabrica.

Assim, acreditamos que a revisão da psicologia comunitária e do seu conceito de comunidade não passa necessariamente pelo abandono dos espaços urbanos que foram local de origem de sua formação, como as comunidades periféricas populares. Há necessidade de reencontrar as potencialidades desses lugares, mesmo que nestes ainda encontremos engrenagens assistencialistas. Compreendemos que, nos enlaces possíveis entre psicologia comunitária e teatro, as percepções e sensações advindas com a experimentação teatral desterritorializam o pensamento, favorecendo um campo de atuação à psicologia para o agenciamento das diferenças. Nos trilhos do prolongamento e da migração dos efeitos estéticos da arte, o psicólogo trabalha junto às redes e aos grupos comunitários no intuito de cooperar na construção das idéias e objetivos coletivos, e na viabilização dos meios de liberação dos desejos ativados nas tramas da comunidade.

Enfim, à psicologia comunitária cabe a compreensão de que a comunidade popular, mais que lugar social marcado pelas carências, é lugar de produção de desejo. Cabe ao psicólogo agenciar os fluxos desejantes, como diversas iniciativas artísticas têm revelado possível para a reinvenção da subjetividade e dos territórios urbanos. Seu desafio é atentar para esse desejo, geralmente obliterado em meio aos projetos que buscam preencher os vazios e as carências de saúde, moradia, escolaridade etc. (que também são fundamentais à construção de um mundo novo, mas que não esgotam esse mundo). $\mathrm{O}$ desejo não pode ser apenas desejo de não ser oprimido; como diz Deleuze, "nunca se fez um desejo com um não querer" (Deleuze \& Parnet, 1998, p. 112).

A abertura da cena e do teatro em geral aos fluxos da comunidade, suas forças e seus desejos, convida a psicologia a se deixar contaminar pela arte, e apostar em seu agenciamento como máquina-desejante. Se nossa psicologia é social e comunitária, também no social o desejo habita e se agita. Partilhar o sensível é assumir o desejo como matéria de ação política, tanto para os artistas quanto para os profissionais da subjetividade. Por onde tem passado o desejo na psicologia comunitária? Talvez seja aí, neste território ainda pouco explorado do nosso campo, que conseguiremos, com maior fecundidade, deslocar e recolocar nossos problemas.

\section{Agradecimento}

As autoras agradecem o apoio da Fundação Coordenação de Aperfeiçoamento de Pessoal de Nível Superior - CAPES.

\section{Referências}

Arias, J. O. C., \& Nolasco, S. R. (1997). O teatro popular em movimento. Revista de Educação Pública, 6(10), 193-203.

Artaud, A. (1999). O teatro e seu duplo. São Paulo: Martins Fontes.

Baptista, L. A. S. (2005). Arte e subjetividade na experiência teatral: contribuições de Jurema da Pavuna. In A. Maciel, D. Kupermann \& S. H. Tedesco (Orgs.), Polifonias: clínica, política e criação (pp. 150-175). Rio de Janeiro: Contra capa.

Boal, A. (1980). Teatro do oprimido e outras poéticas políticas. Rio de Janeiro: Civilização Brasileira.

Deleuze, G. (1979). Un manifeste de moins. In C. Bene \& G. Deleuze (Orgs.), Superposition (pp. 85-131). Paris: Minuit.

Deleuze, G. (1992). Conversações. São Paulo: 34.

Deleuze, G., \& Guattari, F. (1995). Mil platôs: capitalismo e esquizofrenia. São Paulo: 34 .

Deleuze, G., \& Parnet, C. (1998). Diálogos. São Paulo: Escuta.

Góis, C. W. L. (2005). Psicologia comunitária: atividade e consciência. Fortaleza: Instituto Paulo Freire de Estudos Psicossociais.

Guénoun, D. (2003). A exibição das palavras: uma idéia (política) do teatro. Rio de Janeiro: Teatro do Pequeno Gesto.

Guénoun, D. (2004). O teatro é necessário? São Paulo: Perspectiva.

Moreno, J. L. (1987). Psicodrama. São Paulo: Cultrix.

Negri, A. (2005). A constituição do comum. Obtido em 3 de agosto de 2007, de http://fabiomalini.wordpress.com/2007/03/25/a-constituicao-do-comumpor-antonio-negri.

Nunes, S. B. (2004). Boal e Bene: contaminações para um teatro menor. Tese de doutorado não-publicada, Pontifícia Universidade Católica de São Paulo, São Paulo.

Olivier, L. (2007). O teatro e seus benefícios. Obtido em 20 de junho de 2007, de http://loudelivier.com.br/materias/teatro.htm.

Pelbart, P. P. (2000). A vertigem por um fio: políticas da subjetividade contemporânea. São Paulo: Iluminuras.

Pelbart, P. P. (2003). Vida capital: ensaios de biopolítica. São Paulo: Iluminuras.

Rancière, J. (2005a). A partilha do sensivel: estética e politica. São Paulo: $\mathrm{EXO} / 34$.

Rancière, J. (2005b). Política da arte. Obtido em 26 de janeiro de 2007, de http:// www.sescsp.org.br/sesc/images/upload/conferencias/206.rtf.

Rolnik, S. (2003). O ocaso da vítima: para além da cafetinagem da criação e de sua separação da resistência. Obtido em 5 de maio 2007, de http://www. rizoma.net/interna.php?id $=155 \&$ secao $=$ artefato.

Sawaia, B. B. (1996). Comunidade: a apropriação científica de um conceito tão antigo quanto a humanidade. In R. H. F. Campos (Org.), Psicologia social comunitária: da solidariedade à autonomia (pp. 35-53). Petrópolis: Vozes.

Stanislavski, C. (1976). A construção da personagem. Rio de Janeiro: Civilização Brasileira.

Tönnies, F. (1989). Comunidade e sociedade. In M. B. Cruz (Org.), Teorias sociológicas (pp. 511-517). Lisboa: FCG. (Texto original publicado em 1887) 
1 Falamos de intercessão segundo o entendimento de Deleuze (1992). O autor nos traz a idéia dos intercessores, que seriam elementos (coisas, pessoas, idéias) que se encontram em dupla captura, cada qual roubando do outro algo que o altera e permite a criação de novas formas. Um intercessor é algo que permite a expressão pelo contraste entre variações: "Eu preciso de meus intercessores para me exprimir, e eles jamais se exprimiriam sem mim: sempre se trabalha em vários, mesmo quando isso não se vê" (Deleuze, 1992, p. 156).

2 A tradução deste trecho é das autoras.

Tatiana Gomes da Rocha, mestre em Psicologia pelo Programa de Pós-Graduação em Psicologia da Universidade Federal do Rio de Janeiro, é doutoranda neste mesmo programa. Endereço para correspondência: Rua São Clemente, 185, ap. 808, Bloco 2 (Botafogo); Rio de Janeiro, RJ; CEP 22260-001. Tels: (21) 25389045 / (21) 8885-9045. E-mails: tgr_girassol@yahoo.com.br; tati_girassol@hotmail.com Virginia Kastrup, doutora em Psicologia Clínica pela Pontifícia Universidade Católica de São Paulo, é professora no Programa de Pós-Graduação em Psicologia da Universidade Federal do Rio de Janeiro. Email: vkastrup@terra.com.br 